\title{
Molecular Understanding of the Activation of CB1 and Blockade of TRPV1 Receptors: Implications for Novel Treatment Strategies in Osteoarthritis
}

\author{
Jakub Mlost ${ }^{1,2}$, Magdalena Kostrzewa ${ }^{1}$, Natalia Malek ${ }^{1}$ and Katarzyna Starowicz ${ }^{1,2, *}$ \\ 1 Laboratory of Pain Pathophysiology, Department of Pain Pharmacology, Institute of Pharmacology Polish \\ Academy of Sciences, 31-343 Krakow, Poland; mlost13@gmail.com (J.M.); m.kostrzewka@gmail.com (M.K.); \\ en.malek@gmail.com (N.M.) \\ 2 Department of Neurochemistry, Institute of Pharmacology Polish Academy of Sciences, \\ 31-343 Krakow, Poland \\ * Correspondence: starow@if-pan.krakow.pl; Tel.: +48-12-662-3206
}

Received: 14 December 2017; Accepted: 19 January 2018; Published: 24 January 2018

\begin{abstract}
Osteoarthritis (OA) is a joint disease in which cartilage degenerates as a result of mechanical and biochemical changes. The main OA symptom is chronic pain involving both peripheral and central mechanisms of nociceptive processing. Our previous studies have implicated the benefits of dual- over single-acting compounds interacting with the endocannabinoid system (ECS) in OA treatment. In the present study, we focused on the specific molecular alterations associated with pharmacological treatment. OA was induced in Wistar rats by intra-articular injection of $3 \mathrm{mg}$ of monoiodoacetate (MIA). Single target compounds (URB597, an FAAH inhibitor, and SB366791, a TRPV1 antagonist) and a dual-acting compound OMDM198 (FAAH inhibitor/TRPV1 antagonist) were used in the present study. At day 21 post-MIA injection, rats were sacrificed $1 \mathrm{~h}$ after i.p. treatment, and changes in mRNA expression were evaluated in the lumbar spinal cord by RT-qPCR. Following MIA administration, we observed 2-4-fold increase in mRNA expression of targeted receptors (Cnr1, Cnr2, and Trpv1), endocannabinoid degradation enzymes (Faah, Ptgs2, and Alox12), and TRPV1 sensitizing kinases (Mapk3, Mapk14, Prkcg, and Prkaca). OMDM198 treatment reversed some of the MIA effects on the spinal cord towards intact levels (Alox12, Mapk14, and Prkcg). Apparent regulation of ECS and TRPV1 in response to pharmacological intervention is a strong justification for novel ECS-based multi-target drug treatment in OA.
\end{abstract}

Keywords: osteoarthritis; endocannabinoids; OMDM198; TRPV1; sensitization

\section{Introduction}

Osteoarthritis (OA) is a chronic joint disease in which cartilage degenerates as a result of its mechanical and biochemical changes followed by a low-grade inflammatory response [1]. On the molecular level, $\mathrm{OA}$ is characterized by collagen matrix disorganization and a decrease in proteoglycan content within the cartilage. Without the protective effects of the proteoglycans, the collagen fibres of the joint tissue become susceptible to degradation and thus exacerbate this process. Breakdown products when released into the extracellular matrix can evoke an inflammatory response in the synovium and therefore lead to a painful sensation on the peripheral level [2]. The hallmark symptom of osteoarthritis is pain, which is a mixed phenomenon involving nociceptive and neuropathic mechanisms at both the peripheral and central levels [3]. Indeed, patients with OA often develop allodynia and have lowered pain thresholds at locations distant from the place of the injury, suggesting an additional neuropathic mechanism [4].

Unfortunately, the current understanding of OA pathophysiological mechanisms has not led to the development of disease-modifying drugs that are able to stop or slow down disease progression. 
Present-day treatment is mostly based on palliative care, using nonsteroidal anti-inflammatory drugs (NSAIDs) such as ibuprofen, naproxen or diclofenac. However, they do not always provide adequate pain relief and may be associated with the onset of central sensitization during OA development [4]. More importantly, the use of NSAIDs is limited because they exert serious side effects on the gastrointestinal system and have cardiovascular effects, especially with prolonged use, including bleeding, ulcers, stroke, and myocardial infarction [5].

Compelling evidence suggests an active participation of the ECS in the pathophysiology of joint pain associated with OA. Cannabinoid receptor type 1 (CB1) agonists were proven to be effective analgesics in various animal models of chronic pain, including OA [6-9]. However, they are similar to NSAIDs and their clinical potential is highly limited by central nervous system-related side effects such as dizziness, memory impairment, euphoria and risk of abuse or addiction [10]. Alternative treatment strategies aimed at ECS stimulation have focused on inhibition of endocannabinoid degradation. This strategy brings various advantages over direct CB1 activation. Increase in endogenous endocannabinoid tone is devoid of psychoactive effects and will probably minimize side effects observed with systemic CB1 activation. Indeed, preclinical research has confirmed the antinociceptive potential of increased endocannabinoid levels together with an absence of cannabimetic effects [11] and has demonstrated that endocannabinoids adaptively dampen nociceptive transmission in OA [12].

Unfortunately, the inhibition of endocannabinoid degradation did not produce satisfactory results in the clinics. This may be due to redundancy in the metabolic pathways of ECS [13] and/or the activity of endocannabinoids at receptors distinct from the cannabinoid receptors [14]. For example, anadamide (AEA) and some of its lipoxygenation products are also highly potent ligands for the transient receptor potential vanilloid 1 (TRPV1) receptor, suggesting an interplay between ECS and the endovanilloid system. TRPV1 co-localizes with CB1 [15-17] and CB2 [18] in nervous tissue. This colocalization may influence pain transmission pathways through intracellular mechanisms. For example, the stimulation of CB1 can either inhibit or potentiate TRPV1 stimulation by its ligands, depending on whether or not the cyclic adenosine monophosphate (cAMP) signalling pathway is concomitantly activated [19]. Studies have shown that TRPV1 sensitivity can be enhanced by phosphorylation through adenylate cyclase and cAMP-dependent protein kinase A (PKA) [20]. It is possible that during inflammation, enhanced cAMP levels lead to TRPV1 phosphorylation through PKA and that CB1 counteracts the sensitization by inhibition of adenylate cyclase [21-23]. In fact, our previous research revealed upregulation of TRPV1 sensitizing factors, mitogen-activated protein kinase (MAPK), PKA and protein kinase C (PKC) in a neuropathic pain model [24]. TRPV1 is also sensitized by proinflammatory factors such as 12- and 15-hydroperoxyeicosatetraenoic acid (12- and 15-HPETE), 12- and 15-hydroxyeicosatetraenoic acid (12- and 15-HETE) and other arachidonic acid metabolites [25]. This means that upon tissue damage and the consequent inflammation, sensitivity of receptors to noxious stimuli increases. Moreover, changes in extracellular environmental $\mathrm{pH}$ impact the neural cell excitability. In acidic conditions, AEA preferentially binds to TRPV1 instead of CB1, leading to membrane depolarization [26].

All this aforementioned evidence supports the hypothesis that in circumstances of Fatty acid amide hydrolase (FAAH) inhibition, the actions of TRPV1 may be enhanced and serve as a contributing factor to the lack of antinociceptive potential of FAAH inhibitors in the clinic. This effect could be omitted by simultaneously combining FAAH inhibition and TRPV1 antagonism. In fact, this strategy was already tested in our laboratory, and it was proven to be effective. Małek et al. demonstrated TRPV1 and FAAH colocalization in dorsal root ganglions (DRGs) and subsequently used OMDM198, a dual FAAH/TRPV1 blocker, in a battery of behavioural experiments on animals with MIA-induced OA. OMDM198 increased the pain threshold in pressure application measurement and restored impaired weigh bearing [27]. The current state of knowledge regarding ECS and endovanilloid interactions highly support the use of dual-target FAAH and TRPV1 blockers on both theoretical and behavioural levels. However, little is known about the actual molecular underpinnings of such compounds. The 
spinal cord is the first central site of sensory processing. The signal transmissions related to pain can be modified by facilitatory and inhibitory interactions in pain pathways. In fact, molecular changes on the spinal cord level contribute to the development of central sensitization phenomenon, resulting in chronic pain [28]. Thus, quantitative evaluation of ECS components in the spinal cord, after OMDM198 stimulation, is the subject of the current study.

\section{Results}

\subsection{Changes in Cnr1, Cnr2, Faah, and Trpv1 Gene Expression in the Lumbar Spinal Cord}

Gene expression analysis was performed in order to characterise changes in ECS components in $\mathrm{OA}$ and their response to pharmacological treatment. MIA injection caused significant upregulation of Cnr1 (Figure 1A), Cnr2 (Figure 1B), Trpv1 (Figure 1C) and Faah (Figure 1D) expression in the lumbar spinal cord. Treatment with OMDM198 and SB366791 further increased Cnr1 (CB1) expression exclusively on the ipsilateral side (6-fold change vs. 4-fold change, when compared to intact animals), whereas URB597 treatment did not affect levels of Cnr1 expression in MIA-treated animals (Figure 1A). Treatment with OMDM198 had no influence on the Cnr2 (CB2) elevated levels; however, SB366791 and URB597 abolished Cnr2 upregulation from 2.8-fold change to 1.8- and 2.2-fold change, respectively on the ipsilateral side (Figure 1B). Furthermore, treatment either with OMDM198, SB366791 or URB597 did not change Trpv1 and Faah expression levels (Figure 1C,D).

\subsection{Changes in Gene Expression of Kinases Involved in TRPV1 Sensitization in the Lumbar Spinal Cord}

For better understating of the molecular mechanisms of OMDM198 superior analgesic potential in the MIA model, we performed experiments aimed at measuring gene expression of several kinases involved in TRPV1 receptor sensitization. The analysis was performed at the lumbar spinal cord level, where sensitization of pain pathways occurs. Our results revealed strong upregulation (around 3-5-fold change) of Mapk3, Mapk14, Prkcg, and Prkaca mRNA expression in the vehicle-treated osteoarthritic animals (Figure 2A-D). Moreover, OMDM198 treatment abolished Mapk14 and Prkcg upregulation (drop from 3.4- and 4-fold change to 2.6- and 2-fold change, respectively, when compared to intact animals) in the ipsilateral side of the spinal cord (Figure 1B,C).

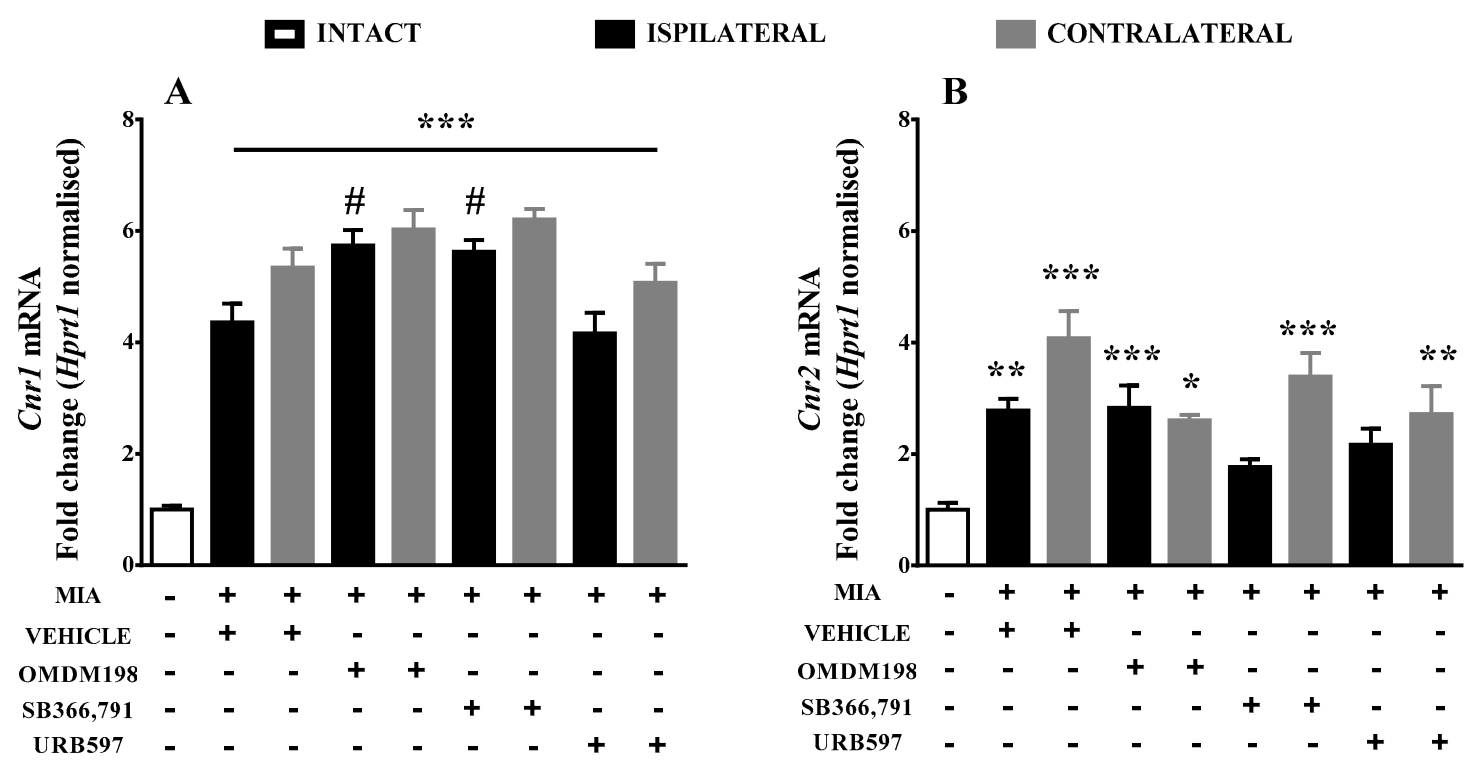

Figure 1. Cont. 

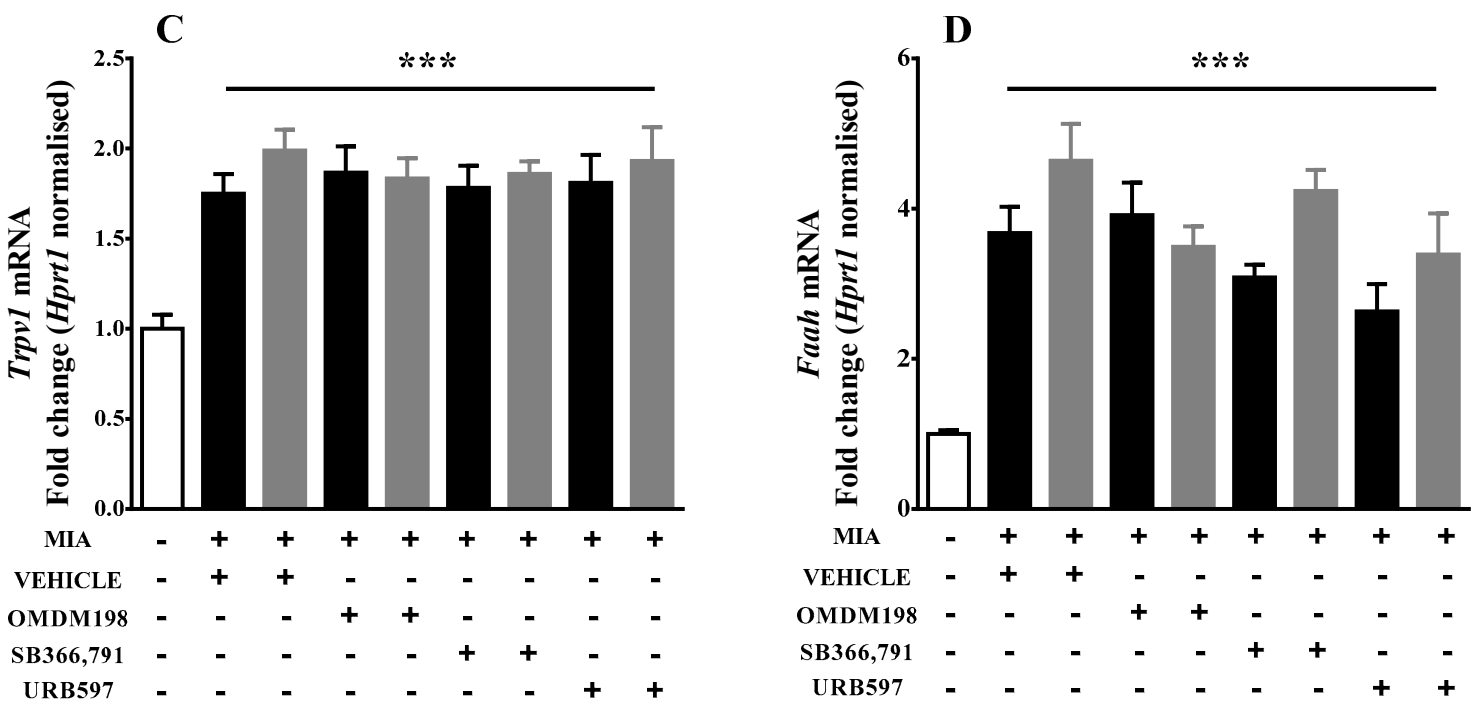

Figure 1. Results of qPCR analysis of Cnr1 (A); Cnr2 (B); Trpv1 (C); and Faah (D); gene expression levels in the dorsal part of the lumbar spinal cord after MIA injection and treatment with OMDM198, SB366791 or URB597. Samples were collected 21 days after MIA injection, $1 \mathrm{~h}$ after i.p. administration of OMDM198, SB366791, URB597 or vehicle. Data are presented as the mean \pm SEM and represent normalized averages derived from 6-10 samples for each group. The results are presented as a fold change normalized to the expression of the reference gene Hprt1 compared to the intact animals. Statistical analysis was performed using one-way ANOVA followed by Bonferroni post hoc tests. Values with $p<0.05$ were considered significant. * Denotes significant differences vs. intact; \# denotes significant differences vs. the same side of the vehicle-treated osteoarthritic animals. ${ }^{* *}, * * *, * * *$ denote higher significance levels.

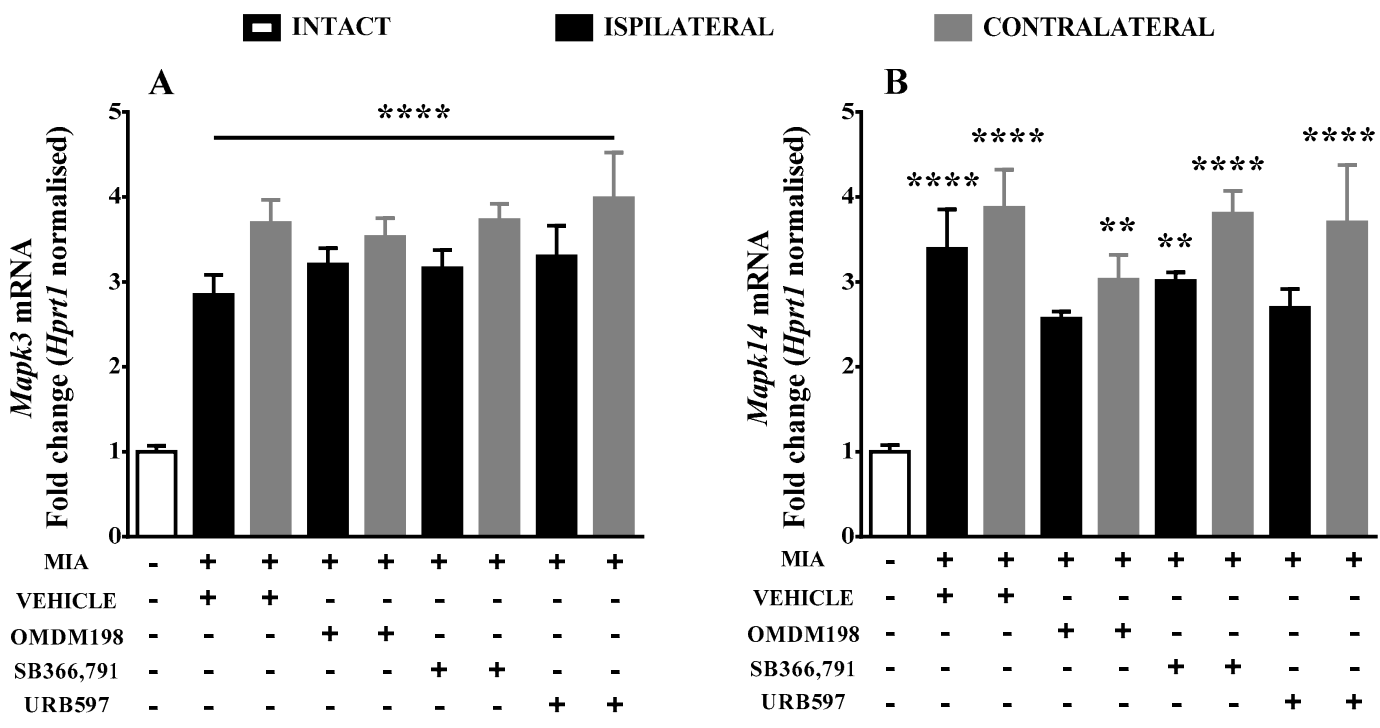

Figure 2. Cont. 

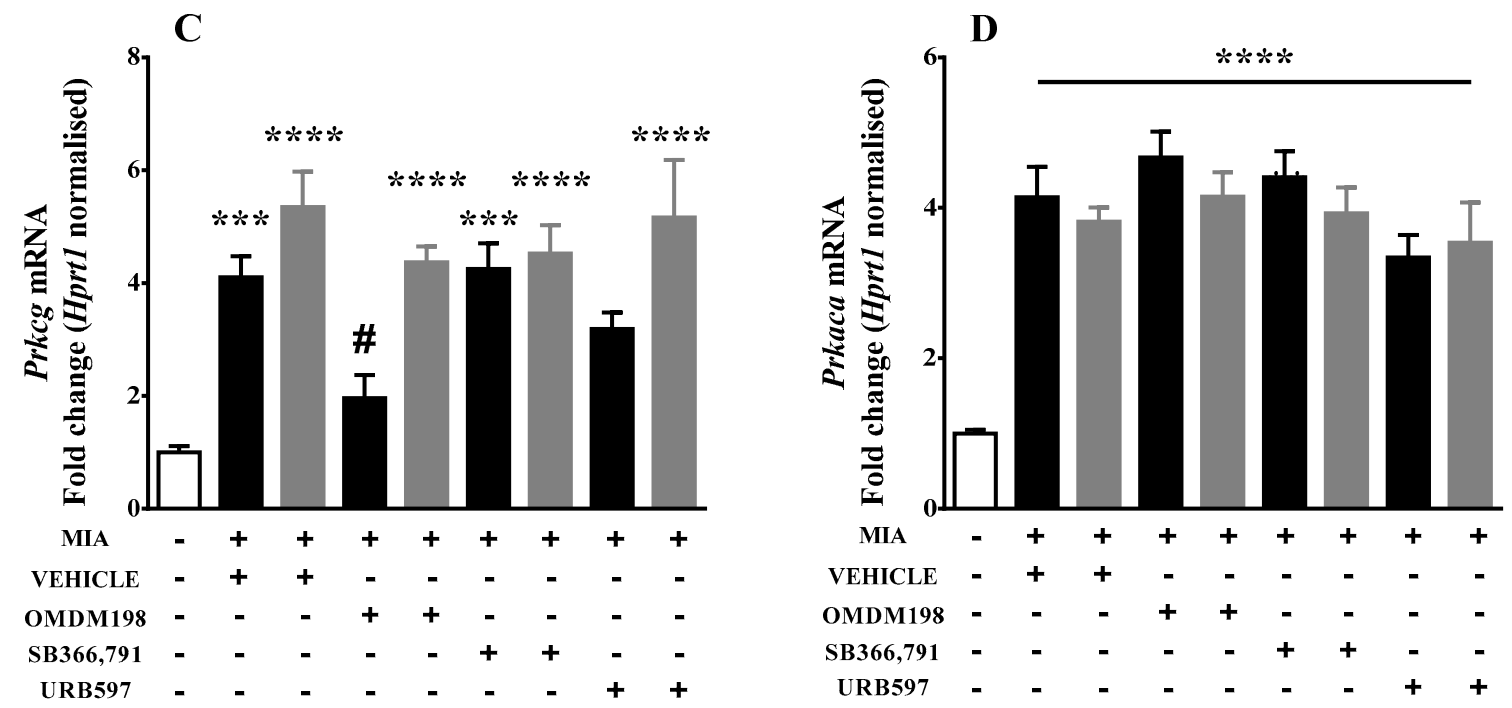

Figure 2. Results of qPCR analysis of Mapk3 (A); Mapk14 (B); Prkcg (C); and Prkaca (D) gene expression levels in the lumbar spinal cord after MIA injection and treatment with OMDM198, SB366791 or URB597. Samples were collected 21 days after MIA injection, $1 \mathrm{~h}$ after i.p. administration of OMDM198, SB366791, URB597 or vehicle. Data are presented as the mean \pm SEM and represent normalized averages derived from 6-10 samples for each group. The results are presented as a fold change normalized to the expression of a reference gene Hprt1 compared to the intact animals. Statistical analysis was performed using one-way ANOVA followed by Bonferroni post hoc tests. Values with $p<0.05$ were considered significant. ${ }^{*}$ Denotes significant differences vs. intact; \# denotes significant differences vs. the same side of the vehicle-treated osteoarthritic animals. ${ }^{* *}, * * *, * * *$ denote higher significance levels.

\subsection{Changes of the AEA Alternative Degrading Enzymes Gene Expression in the Lumbar Spinal Cord}

Finally, we decided to look further at enzymes involved in alternative degradation pathways of AEA for better understanding of FAAH inhibition consequences in OA. Osteoarthritic pain led to an upregulation of mRNA encoding enzymes of anandamide alternative synthesis pathways in the lumbar spinal cord (Figure 3). The abundance of Alox12 mRNA was significantly increased on the ipsi- and contralateral side in MIA animals treated with vehicle (Figure 3A), 2-fold and 2.7-fold increase respectively. The Alox12 upregulation was reduced by half following OMDM198 administration. Statistically significant changes were also observed on the contralateral side after SB366791 administration (2-fold increase) and after URB597 treatment (2.3-fold increase) (Figure 3A). Ptgs2 (COX2) transcript levels increased 4-fold in OA rats compared with the intact animals (Figure 3B), and none of the tested compounds had an influence on it. Authors own results showed no significant changes in the expression of Alox15 in the lumbar spinal cord at day 21 during OA development. We did not elucidate further pharmacological effects of this gene. 


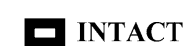

A

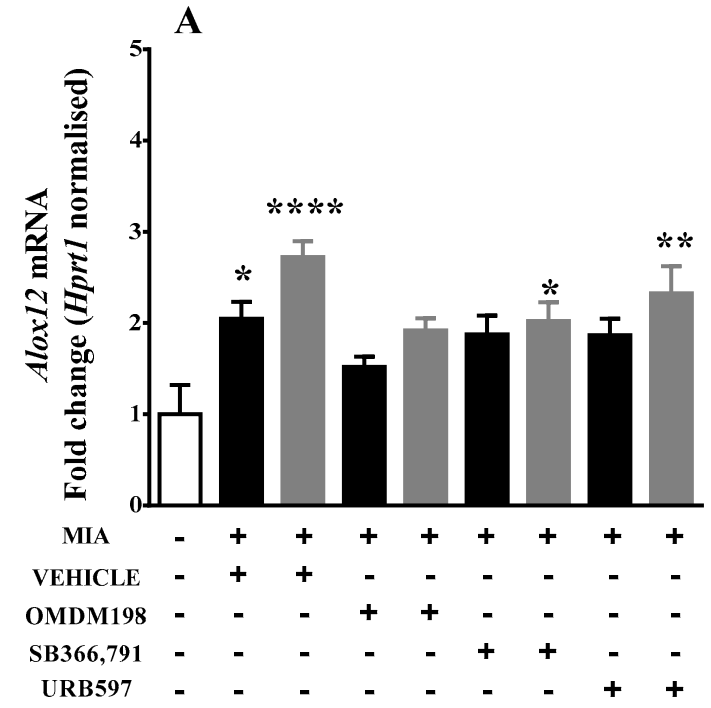

ISPILATERAL

CONTRALATERAL
B

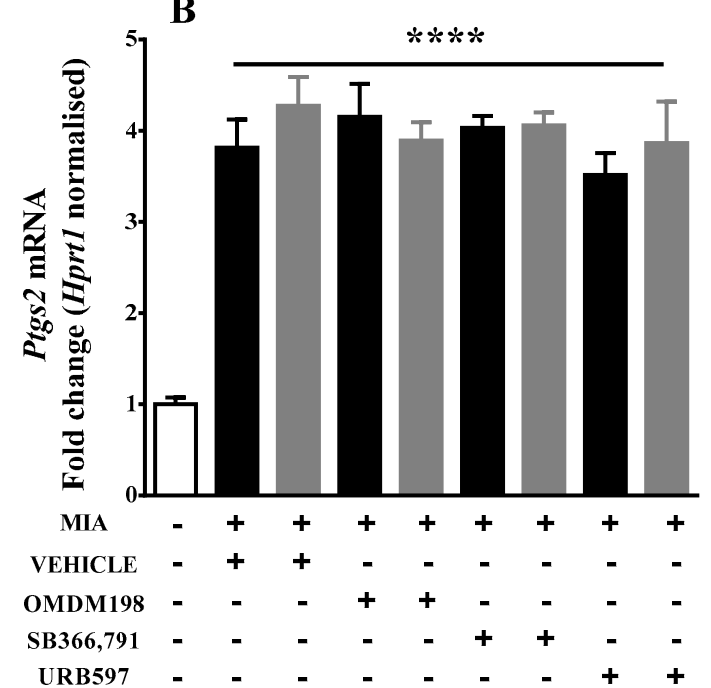

Figure 3. Results of qPCR analysis of Alox12 (A) and Ptgs2 (B) gene expression levels in the lumbar spinal cord after MIA injection and treatment with OMDM198, SB366791 or URB597. Samples were collected 21 days after MIA injection, $1 \mathrm{~h}$ after i.p. administration of OMDM198, SB366791, URB597 or vehicle. Data are presented as the mean \pm SEM and represent normalized averages derived from 6-10 samples for each group. The results are presented as a fold change normalized to the expression of a reference gene Hprt1 compared with the intact animals. Statistical analysis was performed using one-way ANOVA followed by Bonferroni post hoc tests. Values with $p<0.05$ were considered significant. ${ }^{*}$ Denotes significant differences vs. intact. ${ }^{* *}, * * * * * * *$ denote higher significance levels.

\section{Discussion}

OA is a debilitating disease with an underlying pathophysiology that is complex and not entirely understood. Joint degeneration seems to be a result of mixed environmental and genetic features. Due to the lack of self-healing capacity of articular cartilage, OA is among the most challenging joint diseases. The goal of OA research is to search for new therapeutic strategies that could prevent, reduce or stop the progression of the disease or, alternatively, resolve the existing damage to the joint. Studies have driven the identification of promising targets for OA treatment involving inflammation and/or nerve sensitization mechanisms in OA development, rationalizing our focus on the role of ECS as useful for the treatment of OA. Here, we have presented results describing molecular changes in ECS components in a MIA model of OA and provide novel insights regarding the pharmacological effects of endocannabinoids on OA considering ECS redundancy.

First, our qPCR analysis revealed strong mRNA upregulation in all the studied ECS components (Cnr1, Cnr2, Faah and Trpv1) on both sides of the lumbar spinal cord in response to OA induction (MIA treatment). That implies strong activation of ascending pain pathways in the spinal cord and a significant role of ECS in pain transmission. This observation is consistent with previous experiments revealing increased ECS tone as a pathophysiological mechanism involved in silencing sensitized pain pathways due to inflammation or nerve injury $[29,30]$. Our recent study by Małek et al. revealed that OMDM198 exerts more pronounced analgesia than single target drugs and this effect is blocked by a CB1 antagonist (AM251) [27]. In the present study, further increases in Cnr1 expression were observed following TRPV1 blockade with both multi- and single-target drugs. CB1 upregulation may lead to a significant increase in efficacy and an analgesic potential of partial agonists [31], such as AEA, and, therefore, may provide an explanation for pronounced antinociceptive effects of OMDM198 in comparison to the single target FAAH inhibitor, URB597. These results hold a good promise for further research upon ECS as a potential treatment target in OA, because ECS stimulation could prevent or 
reduce this promiscuous form of pain plasticity. Additionally, the observed increase in Trpv1 expression in the spinal cord confirms its role in the sensitization of pain pathways [32] and represents a suitable indicator for the use of dual-target drugs for OA treatment.

Increases in mRNA expression of kinases involved in TRPV1 sensitization indicates undergoing plasticity in pain pathways on the spinal cord level. This result is consistent with previous results obtained in our laboratory that revealed increased expression of Mapk14, Prkcg, and Prkaca in the peripheral nervous system in a chronic constriction injury model of neuropathic pain [24]. What is even more interesting is the fact that FAAH inhibition by OMDM198 or URB597 partially counteracted Mapk14 and Prkcg upregulation in the ipsilateral side of the spinal cord and might represent their molecular mechanism of action. Ji et al. have shown that intrathecal administration of SB203580, a p38-mitogen-activated protein kinase (encoded by the Mapk14 gene) inhibitor, decreases inflammatory heat hyperalgesia and induces TRPV1 protein upregulation in the DRGs [33,34]. Furthermore, recent research revealed that H89, a PKA (encoded by the Prkaca gene) inhibitor and GF109203X, a PKC $\gamma$ (encoded by the Prkcg gene) inhibitor suppresses TRPV1 externalization in DRGs sensory neuron cultures [35] and that the latter compound is also able to reverse capsaicin-induced pain-related behaviour in MIA rats [36]. Decreases of Mapk14 and Prkcg mRNA levels following FAAH inhibition highlights hopes for new treatment strategies of neuropathic components in rheumatic diseases, as seen with intrathecal administration of $\mathrm{p} 38 \alpha$ MAPK and PKC $\gamma$ inhibitors in a chronic constriction injury model of neuropathic pain $[37,38]$.

An interesting finding of this work is a closer look at the alternative degrading pathways of AEA that could reveal some new insight into endocannabinoid metabolism under pathological conditions and point to beneficial analgesic effects in a therapeutic context. The Alox12 gene is coding lipooxygenase-12, an enzyme involved in the transformation of arachidonate compounds such as arachidonic acid (AEA precursor) or AEA into proinflammatory factors such as 12-HETE (TRPV1 agonist). Previously mentioned research by Kelly et al. has shown elevated levels of 12-HETE in the knee joint and TRPV1 in the spinal cord of MIA rats [39]. Moreover, these studies confirmed a functional role of TRPV1 in a lowered mechanical threshold of knee joint afferents together with the analgesic potential of a TRPV1 blockade [39]. In the present study on a MIA model of OA, we observed a bilateral increase in Alox12 expression in the spinal cord. These data add up to the relevance of the endovanilloid system on the spinal level of pain transmission in OA pathophysiology and further indicate the usefulness of TRPV1 antagonists as analgesic agents. Additionally, we observed bilateral attenuation of Alox12 upregulation following OMDM198 treatment but not after treatment with any of the single-target drugs, which acted only partially.

Another enzyme capable of AEA degradation is COX2 encoded by the Ptgs 2 gene. COX2 is induced in inflammatory conditions and the main metabolic pathway involves arachidonic acid transformation into proinflammatory prostaglandin 2 (PGE2), which is another factor promoting TRPV1 upregulation [35]. AEA may undergo direct oxygenation by COX2, resulting in the formation of prostamide F2 $\alpha$ (PGF2 $\alpha$ ) [40], a mediator of inflammation and pain [41]. It was shown that PGF2 $\alpha$ metabolite levels are increased in OA patients' serum and synovial fluid [42]. PGF2 $\alpha$ exerts profibrotic action by induction of collagen production that can further limit joint movement [43]. On the other hand, COX2 inhibition reversed spinal neuron hyperexcitability during inflammation [44] and produced endocannabinoid-mediated spinal antinociception in a CB1-dependent manner [45]. Our experiments demonstrated an increase in Ptgs2 expression on the spinal level. Unfortunately, its expression was not altered by any of the tested drugs. It may be worthwhile to study further a combined administration of OMDM198 with COX2 inhibitors or dual inhibition of FAAH and COX2 as an even more complex treatment strategy for osteoarthritis. Indeed, a recent work by Palermo et al. addressed the synthesis and the potential anti-inflammatory use of FAAH and COX-2 multi-target ligand, ARN2508 [46]. 
To sum up, OMDM198 seems to exert its main effects through the antinociceptive profile of FAAH inhibition (indirect CB1 activation) and TRPV1 antagonism [27] but beyond that lies a complicated network of intercellular interactions. A summary of the proposed mechanisms of OMDM198 action is presented in Figure 4. Recent evidence pinpoints the role of inflammation in OA pathophysiology (reviewed in de Lange-Brokaar et al. 2012) [47], and the hereby presented results further identify its role in OA pathology. Our data recognized an increase in Ptgs2 mRNA and its downstream effectors such as Prkaca, Prkcg and Mapk14 [35], which could result in the observed TRPV1 upregulation, suggesting spinal sensitization as an important contributor to the development and progression of a neuropathic component of $\mathrm{OA}$. These results are consistent with recent reports from two independent research groups $[35,36]$ who neatly demonstrated that PGE2 and protein kinases are responsible for TRPV1 sensitization in vivo on a peripheral level. Even though we did observe abolishment of TRPV1 sensitizing factors upregulation as a result of FAAH inhibition, we were not able to observe any significant changes in Ptgs2 mRNA levels.

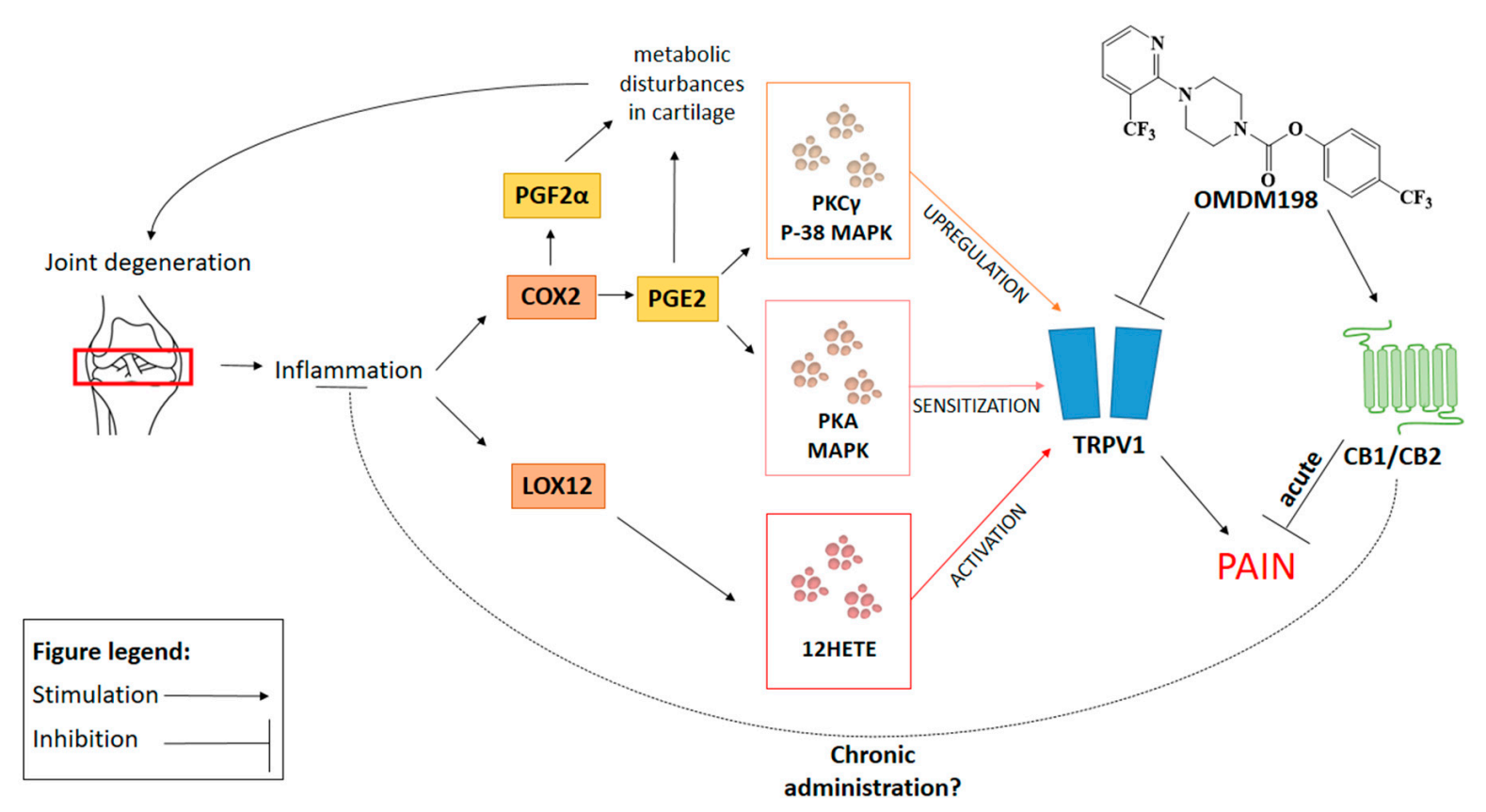

Figure 4. Schematic representation of the hypothetical molecular mechanism underlying OMDM198's therapeutic potential in OA treatment.

A summary of all gene expression changes following pharmacological treatment with FAAH inhibitor and/or TRPV1 antagonist can be found in Tables 1 and 2. However, it is noteworthy to mention that the observed effects were associated with acute administration of the dual acting compound, OMDM-198, while chronic OMDM-198 treatment could suppress inflammation through ECS and decrease the pain-sensitizing effectors of COX2 metabolism. 
Table 1. Summary of observed pharmacological effects upon mRNA expression in the ipsilateral part of lumbar spinal cord. Data is presented as mean fold change \pm SEM in comparison to intact animals. Values in brackets represent number of animals in given group. Values with $p<0.05$ were considered significant. * Denotes significant differences vs. intact, whereas \# denotes significant differences vs. the same side of the vehicle-treated osteoarthritic animals. ${ }^{* *}, * * *, * * *$ denote higher significance levels. $\uparrow$ denotes an increase vs. intact group, whereas a second $\uparrow$ denotes an increase vs. vehicle group. $\downarrow$ denotes a decrease vs. vehicle.

\begin{tabular}{|c|c|c|c|c|}
\hline Ipsi & Vehicle & OMDM198 & SB366791 & URB597 \\
\hline Cnr2 & $2.77949 \pm 0.21(9)^{* * \uparrow}$ & $2.829189 \pm 0.4(10)^{* * * \uparrow}$ & $1.76802 \pm 0.14(9)$ & $2.166964 \pm 0.29(7) \uparrow$ \\
\hline Faah & $3.67581 \pm 0.35(10)^{* * * \uparrow}$ & $3.91468 \pm 0.43(10)^{* * * \uparrow}$ & $3.08223 \pm 0.17(9)^{* * * \uparrow}$ & $2.63209 \pm 0.36(7)^{* * * \uparrow}$ \\
\hline Mapk3 & $2.847 \pm 0.23(10)^{* * * * \uparrow}$ & $3.20392 \pm 0.19(10)^{* * * * \uparrow}$ & $3.16103 \pm 0.21(10)^{* * * * \uparrow}$ & $3.30138 \pm 0.36(7)^{* * * * \uparrow}$ \\
\hline Mapk14 & $3.38744 \pm 0.46(10)^{* * * * \uparrow}$ & $2.56705 \pm 0.08(8)$ & $3.01161 \pm 0.1(8)^{* * \uparrow}$ & $2.69419 \pm 0.22(6) \uparrow$ \\
\hline alox12 & $2.045551 \pm 0.18(10)^{* \uparrow}$ & $1.519128 \pm 0.11(10)$ & $1.876361 \pm 0.2(10)$ & $1.866132 \pm 0.18(7)$ \\
\hline Ptgs2 & $3.81417 \pm 0.31(10)^{* * * * \uparrow}$ & $4.15244 \pm 0.36(10)^{* * * * \uparrow}$ & $4.03079 \pm 0.13(10)^{* * * * \uparrow}$ & $3.5141 \pm 0.24(7)^{* * * * \uparrow}$ \\
\hline
\end{tabular}

Table 2. Summary of observed pharmacological effects upon mRNA expression in the contralateral part of lumbar spinal cord. Data is presented as mean fold change \pm SEM in comparison to intact animals. Values in brackets represent number of animals in given group. Values with $p<0.05$ were considered significant. ${ }^{*}$ Denotes significant differences vs. intact. ${ }^{* *}, * * * * * *$ denote higher significance levels. $\uparrow$ denotes an increase vs. intact group.

\begin{tabular}{ccccc}
\hline Contra & Vehicle & OMDM198 & SB366791 & URB597 \\
\hline Cnr1 & $5.34396 \pm 0.34(8)^{* * * \uparrow}$ & $6.02753 \pm 0.35(10)^{* * * \uparrow}$ & $6.20558 \pm 0.19(10)^{* * * \uparrow}$ & $5.0704 \pm 0.34(8)^{* * * \uparrow}$ \\
Cnr2 & $4.075169 \pm 0.49(8)^{* * * \uparrow}$ & $2.604934 \pm 0.1(8)^{* \uparrow}$ & $3.388387 \pm 0.42(10)^{* * * \uparrow}$ & $2.717181 \pm 0.5(9)^{* * \uparrow}$ \\
Trpv1 & $1.98928 \pm 0.12(8)^{* * * \uparrow}$ & $1.8344 \pm 0.11(10)^{* * * \uparrow}$ & $1.85948 \pm 0.07(9)^{* * * \uparrow}$ & $1.9315 \pm 0.19(9)^{* * * \uparrow}$ \\
Faah & $4.63649 \pm 0.49(8)^{* * * \uparrow}$ & $3.49026 \pm 0.27(9)^{* * * \uparrow}$ & $4.23487 \pm 0.28(10)^{* * * \uparrow}$ & $3.38967 \pm 0.55(9)^{* * * \uparrow}$ \\
Mapk3 & $3.69186 \pm 0.28(8)^{* * * * \uparrow}$ & $3.52777 \pm 0.22(9)^{* * * * \uparrow}$ & $3.72732 \pm 0.19(10)^{* * * * \uparrow}$ & $3.98384 \pm 0.54(8)^{* * * * \uparrow}$ \\
Mapk14 & $3.87233 \pm 0.45(8)^{* * * * \uparrow}$ & $3.02531 \pm 0.29(10)^{* * \uparrow}$ & $3.80339 \pm 0.27(10)^{* * * * \uparrow}$ & $3.69974 \pm 0.67(9)^{* * * * \uparrow}$ \\
Prkaca & $3.81766 \pm 0.19(7)^{* * * * \uparrow}$ & $4.14995 \pm 0.32(8)^{* * * * \uparrow}$ & $3.92648 \pm 0.34(10)^{* * * * \uparrow}$ & $3.53792 \pm 0.53(9)^{* * * * \uparrow}$ \\
Prkcg & $5.34829 \pm 0.63(8)^{* * * * \uparrow}$ & $4.36753 \pm 0.28(9)^{* * * * \uparrow}$ & $4.52286 \pm 0.5(10)^{* * * *}$ & $5.16141 \pm 1.02(9)^{* * * * \uparrow}$ \\
alox12 & $2.722801 \pm 0.17(8)^{* * * \uparrow}$ & $1.917924 \pm 0.13(9)$ & $2.020144 \pm 0.2(10)^{* \uparrow}$ & $2.324423 \pm 0.3(9)^{* * \uparrow}$ \\
Ptgs2 & $4.27398 \pm 0.32(8)^{* * * * \uparrow}$ & $3.89243 \pm 0.2(9)^{* * * * \uparrow}$ & $4.05906 \pm 0.14(10)^{* * * * \uparrow}$ & $3.86385 \pm 0.46(9)^{* * * * \uparrow}$ \\
\hline
\end{tabular}

\section{Materials and Methods}

\subsection{Animals}

Male Wistar rats (Charles River, Hamburg, Germany) around 55th postnatal day, initially weighing 225-250 g, were used for all experiments. Animals were housed five per cage under a standard $12 \mathrm{~h} / 12 \mathrm{~h}$ light/dark cycle with food and water available ad libitum. All experiments were approved by the Local Bioethics Committee of the Institute of Pharmacology (Cracow, Poland, approval number 938/2012 (date of approval: 28 June 2012).

\subsection{Drugs and Reagents}

URB597, SB366791 were obtained from Tocris Bioscience (Bristol, UK), whereas MIA, dimethyl sulfoxide (DMSO), Cremophor and Tween 80 were obtained from Sigma-Aldrich (Poznan, Poland). The OMDM-198 was synthesized, purified and characterized as described in Morera et al. 2009 [48] (Structure presented on Figure 5). All the reagents were dissolved in a vehicle solution. The vehicle for URB597 was $2 \%$ DMSO, $1 \%$ Tween 80 , and $1 \%$ carboxymethyl cellulose in $0.9 \%$ saline. The vehicle for OMDM198 was 9\% DMSO in 0.9\% saline. The vehicle for SB366791 was 18\% DMSO, 1\% ethanol, and 1\% Tween 80 in $0.9 \%$ saline. 


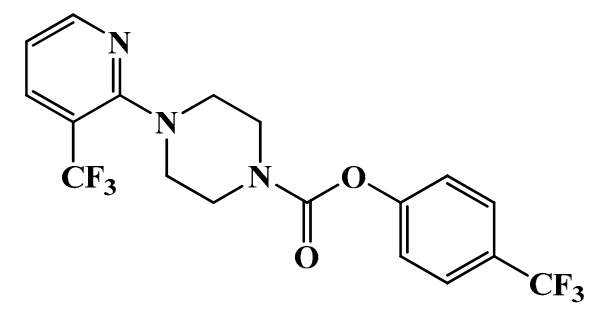

Figure 5. Chemical structure of OMDM198; the compound was synthesized on demand at the Department of Chemistry and Technology of Drugs in Sapienza University of Rome in Giorgio Ortar's laboratory. All other compounds are commercially available.

\subsection{OA Induction}

Animals were deeply anaesthetized with $5 \%$ isoflurane in $100 \% \mathrm{O}_{2}(4.5 \mathrm{~L} / \mathrm{min})$ until the flexor withdrawal reflex was abolished. The skin overlying the right knee joint was shaved and swabbed with $100 \%$ ethanol. A 27 -gauge needle was introduced into the joint cavity through the patellar ligament and $3 \mathrm{mg}$ of MIA, which is an irreversible NADPH inhibitor, diluted in $50 \mu \mathrm{L} 0.9 \%$ saline was injected into the joint (intra-articular, i.a.) to induce OA-like lesions. MIA inhibits chondrocyte glycolysis and produces cartilage degeneration and subchondral bone alterations. The MIA model reproduces osteoarthritis-like histological lesions and functional impairment similar to that observed in human disease [49]. The rats were sacrificed at day 21 after MIA injection.

\subsection{Treatment Paradigm}

Rats were injected intraperitonealy (i.p.) with OMDM198 (the dual FAAH inhibitor and TRPV1 blocker) and respective single target compounds, SB366791 (TRPV1 antagonist) and URB597 (FAAH inhibitor) or vehicle, $1 \mathrm{~h}$ before decapitation at doses 1,2 , and $5 \mathrm{mg} / \mathrm{kg}$, respectively. The vehicle group received a respective volume of $18 \%$ DMSO, $1 \%$ ethanol, and $1 \%$ Tween 80 in $0.9 \%$ saline. Moreover, a group of intact animals was used as a reference.

\subsection{Tissue Isolation}

After decapitation, L3-L5 dorsal lumbar spinal cord was collected from both the ipsilateral and contralateral side to the injury. Tissue samples were placed in individual tubes, frozen in liquid nitrogen, and stored at $-80{ }^{\circ} \mathrm{C}$ until RNA and protein isolation.

\subsection{RNA Preparation}

Tissue was placed in $1 \mathrm{~mL}$ of TRIzol reagent (Invitrogen, Carlsbad, CA, USA). RNA isolation was performed according to Chomczynski's method [50]. Tissue was homogenized in a tissue lyser (Qiagen Inc., Hilden, Germany). RNA was denaturated for $3 \mathrm{~min}$ at $70^{\circ} \mathrm{C}$. RNA concentration was measured using a NanoDrop ND-100 Spectrometer (Thermo Scientific, Wilmington, DE, USA). Each sample was equalized to a concentration of $1 \mu \mathrm{g} / \mu \mathrm{L}$ and reverse transcribed to cDNA using iScript Reverse Transcription Supermix (BioRad, Hercules, CA, USA) according to the manufacturer's protocol in a $20 \mu \mathrm{L}$ total volume. The complete reaction mix was incubated in a thermal cycler according to the manufacturer's protocol.

\subsection{Quantitative Polymerase Chain Reaction ( $q P C R$ )}

The reaction was performed with TaqMan probes and TaqMan Universal PCR Super Mix (Bio-Rad, Hercules, CA, USA) in a thermocycler C1000 ${ }^{\mathrm{TM}}$ CFX96 ${ }^{\mathrm{TM}}$ Real-Time system (Bio-Rad, Hercules, CA, USA) according to the manufacturer's protocol: denaturation $30 \mathrm{~s}$ at $95{ }^{\circ} \mathrm{C}$ and then 40 cycles of: denaturation, $5 \mathrm{~s}$ at $95{ }^{\circ} \mathrm{C}$, annealing, extension and plate read, $30 \mathrm{~s}$ at $60{ }^{\circ} \mathrm{C}$. The expression of the hypoxanthine phosphoribosyltransferase 1 (Hprt1) transcript with a stable level between the 
control and investigated groups was quantified to control for variation in the cDNA amounts. As the quantity of PCR rises, the fluorescence coming from the probes used in the reaction rises proportionally. That allows us to monitor the amount of PCR product in real time between cycles. The threshold cycle (CT) value (cycle during which fluorescence exceeds the threshold value) for each gene was normalized with the CT value of the Hprt1 reference gene. RNA abundance was calculated as $2^{-\Delta C t}$. The results are presented as a fold change proportional to the expression level in intact animals. The following assays (TaqMan Gene Expression Assays, Life Technologies, Waltham, MA, USA) were used in the experiment: Rn01527840m1 (Hprt1), Rn02758689s1 (Cb1), Rn04342831s1 (Cb2), Rn00583117m1 (Trpv1), Rn00577086m1 (Faah), Rn00440861m1 (Prkcg), Rn01432300g1 (Prkaca), Rn00578842m1 (Mapk14), Rn00820922g1 (Mapk3), Rn01483828m1 (Ptgs2), Rn01461082_ml (Alox12). A total number of 10 animals per treatment group was used in the experiment.

\subsection{Statistical Analysis}

The analysis was performed using Prism V.5 (GraphPad Software, Inc., La Jolla, CA, USA). Changes in mRNA levels in the lumbar spinal cord were analysed using one-way analyses of variance. A Bonferroni post hoc test was used to compare the effects of MIA injection (vehicle-treated osteoarthritic group) to the intact group and pharmacological treatments for the vehicle-treated osteoarthritic group (ipsilateral or contralateral, respectively). The data were considered significant only when $p<0.05 .{ }^{*}$ denotes significant differences vs. intact, whereas \# denotes significant differences vs. vehicle treated osteoarthritic animals. ${ }^{* *},{ }^{* * *},{ }^{* * * *}$ denote higher significance levels, whereas a horizontal line emphasizes significant differences between all treatments (including vehicle treated) groups vs. intact. Outlier values above/below mean $\pm 2 *$ standard deviation were excluded from the analysis.

\section{Conclusions}

Most pharmacological strategies to this date have been based on a specific single-target strategy that is now proving to be increasingly unsuccessful in treating diseases with a complex aetiology as in the case of OA. It has traditionally been classified as a noninflammatory arthritis; however, the dichotomy between inflammatory and degenerative arthritis is becoming less clear with the recognition of a plethora of ongoing immune processes. Actually, our results shed light on the inflammatory component of OA that is related to TRPV1 sensitization as presented by changes in Trpv1 and mRNA kinase expression together with increases in Alox12 expression. Apparent interplay between articular, immunological and the nervous systems in the pathophysiology of $\mathrm{OA}$ is a strong justification for novel multi-target drug development strategies. Our previous work had already presented the superior antinociceptive potential of OMDM198 over URB597, a FAAH inhibitor, and SB366791, a TRPV1 receptor antagonist. The experiments performed herein bring better understanding of the molecular underpinnings of OMDM198 with pronounced antinociceptive potential and prove its superiority over single-target treatment strategies.

Acknowledgments: This work was supported by the National Science Centre, Poland, Grant SONATA BIS NCN/2012/07/E/NZ7/01269, and statutory funds from the Institute of Pharmacology PAS. Natalia Malek is a recipient of a scholarship from KNOW sponsored by the Ministry of Science and Higher Education, Republic of Poland.

Author Contributions: Jakub Mlost performed the RT-qPCR assays, analysed the results, collected and assembled all the data, conducted the statistical analyses, interpreted the data and wrote the paper; Magdalena Kostrzewa isolated tissue samples and was involved in drafting the manuscript; Natalia Malek induced the MIA model and participated in study design; Katarzyna Starowicz obtained funding, conceived and designed the study, was involved in interpretation of the data, drafting the manuscript and revisions for intellectual content. All authors discussed the results and its implications at all stages and have approved the final version of the manuscript.

Conflicts of Interest: The authors declare no conflict of interest. 


\section{Abbreviations}

$\begin{array}{ll}\text { 2-AG } & \text { 2-arachidonylglycerol } \\ \text { AEA } & \text { Anandamide } \\ \text { cAMP } & \text { Cyclic adenosine monophosphate } \\ \text { CB1 } & \text { Cannabinoid receptor type 1 } \\ \text { CB2 } & \text { Cannabinoid receptor type 2 } \\ \text { COX2 } & \text { Cyclooxygenase-2 } \\ \text { CT } & \text { Threshold cycle } \\ \text { DMSO } & \text { Dimethyl sulfoxide } \\ \text { DRGs } & \text { Dorsal root ganglions } \\ \text { ECS } & \text { Endocannabinoid system } \\ \text { FAAH } & \text { Fatty acid amide hydrolase } \\ \text { HETE } & \text { Hydroxyeicosatetraenoic acid } \\ \text { HPETE } & \text { Hydroperoxyeicosatetraenoic acid } \\ \text { MAPK } & \text { Mitogen-activated protein kinases } \\ \text { MIA } & \text { Monoiodoacetate } \\ \text { NSAIDs } & \text { Nonsteroidal anti-inflammatory drugs } \\ \text { OA } & \text { Osteoarthritis } \\ \text { qPCR } & \text { Quantitive polymerase chain reaction } \\ \text { PGE2 } & \text { Prostaglandine E2 } \\ \text { PGF2 } \alpha & \text { Prostamide F2 } \alpha \\ \text { PKA } & \text { Protein kinase A } \\ \text { PKC } & \text { Protein kinase C } \\ \text { TRPV1 } & \text { Transient receptor potential cation channel subfamily V member 1 }\end{array}$

\section{References}

1. Haseeb, A.; Haqqi, T.M. Immunopathogenesis of osteoarthritis. Clin. Immunol. 2013, 146, 185-196. [CrossRef] [PubMed]

2. Scanzello, C.R.; Goldring, S.R. The role of synovitis in osteoarthritis pathogenesis. Bone 2012, 51, $249-257$. [CrossRef] [PubMed]

3. Kidd, B. Mechanisms of pain in osteoarthritis. HSS J. 2012, 8, 26-28. [CrossRef] [PubMed]

4. Lluch, E.; Torres, R.; Nijs, J.; van Oosterwijck, J. Evidence for central sensitization in patients with osteoarthritis pain: A systematic literature review. Eur. J. Pain 2014, 18, 1367-1375. [CrossRef] [PubMed]

5. Van Walsem, A.; Pandhi, S.; Nixon, R.M.; Guyot, P.; Karabis, A.; Moore, R.A. Relative benefit-risk comparing diclofenac to other traditional non-steroidal anti-inflammatory drugs and cyclooxygenase-2 inhibitors in patients with osteoarthritis or rheumatoid arthritis: A network meta-analysis. Arthritis Res. Ther. 2015, 17, 66. [CrossRef] [PubMed]

6. Bridges, D.; Ahmad, K.; Rice, A.S.C. The synthetic cannabinoid WIN55,212-2 attenuates hyperalgesia and allodynia in a rat model of neuropathic pain. Br. J. Pharmacol. 2001, 133, 586-594. [CrossRef] [PubMed]

7. Schuelert, N.; McDougall, J.J. Cannabinoid-mediated antinociception is enhanced in rat osteoarthritic knees. Arthritis Rheum. 2008, 58, 145-153. [CrossRef] [PubMed]

8. Schuelert, N.; Johnson, M.P.; Oskins, J.L.; Jassal, K.; Chambers, M.G.; McDougall, J.J. Local application of the endocannabinoid hydrolysis inhibitor URB597 reduces nociception in spontaneous and chemically induced models of osteoarthritis. Pain 2011, 152, 975-981. [CrossRef] [PubMed]

9. Schreiber, A.K.; Neufeld, M.; Jesus, C.H.A.; Cunha, J.M. Peripheral antinociceptive effect of anandamide and drugs that affect the endocannabinoid system on the formalin test in normal and streptozotocin-diabetic rats. Neuropharmacology 2012, 63, 1286-1297. [CrossRef] [PubMed]

10. Danovitch, I.; Gorelick, D.A. State of the art treatments for cannabis dependence. Psychiatr. Clin. N. Am. 2012, 35, 309-326. [CrossRef] [PubMed] 
11. Ghosh, S.; Kinsey, S.G.; Liu, Q.S.; Hruba, L.; McMahon, L.R.; Grim, T.W.; Merritt, C.R.; Wise, L.E.; Abdullah, R.A.; Selley, D.E.; et al. Full Fatty Acid Amide Hydrolase Inhibition Combined with Partial Monoacylglycerol Lipase Inhibition: Augmented and Sustained Antinociceptive Effects with Reduced Cannabimimetic Side Effects in Mice. J. Pharmacol. Exp. Ther. 2015, 354, 111-120. [CrossRef] [PubMed]

12. Sagar, D.R.; Staniaszek, L.E.; Okine, B.N.; Woodhams, S.; Norris, L.M.; Pearson, R.G.; Garle, M.J.; Alexander, S.P.H.; Bennett, A.J.; Barrett, D.A.; et al. Tonic modulation of spinal hyperexcitability by the endocannabinoid receptor system in a rat model of osteoarthritis pain. Arthritis Rheum. 2010, 62, 3666-3676. [CrossRef] [PubMed]

13. Piscitelli, F.; di Marzo, V. "Redundancy" of endocannabinoid inactivation: New challenges and opportunities for pain control. ACS Chem. Neurosci. 2012, 3, 356-363. [CrossRef] [PubMed]

14. Di Marzo, V.; de Petrocellis, L. Why do cannabinoid receptors have more than one endogenous ligand? Philos. Trans. R. Soc. Lond. B Biol. Sci. 2012, 367, 3216-3228. [CrossRef] [PubMed]

15. Ahluwalia, J.; Urban, L.; Bevan, S.; Nagy, I. Anandamide regulates neuropeptide release from capsaicin-sensitive primary sensory neurons by activating both the cannabinoid 1 receptor and the vanilloid receptor 1 in vitro. Eur. J. Neurosci. 2003, 17, 2611-2618. [CrossRef] [PubMed]

16. Cristino, L.; de Petrocellis, L.; Pryce, G.; Baker, D.; Guglielmotti, V.; di Marzo, V. Immunohistochemical localization of cannabinoid type 1 and vanilloid transient receptor potential vanilloid type 1 receptors in the mouse brain. Neuroscience 2006, 139, 1405-1415. [CrossRef] [PubMed]

17. Starowicz, K.; Makuch, W.; Korostynski, M.; Malek, N.; Slezak, M.; Zychowska, M.; Petrosino, S.; de Petrocellis, L.; Cristino, L.; Przewlocka, B.; et al. Full Inhibition of Spinal FAAH Leads to TRPV1-Mediated Analgesic Effects in Neuropathic Rats and Possible Lipoxygenase-Mediated Remodeling of Anandamide Metabolism. PLoS ONE 2013, 8, e60040. [CrossRef] [PubMed]

18. Anand, U.; Otto, W.R.; Sanchez-Herrera, D.; Facer, P.; Yiangou, Y.; Korchev, Y.; Birch, R.; Benham, C.; Bountra, C.; Chessell, I.P.; et al. Cannabinoid receptor CB2 localisation and agonist-mediated inhibition of capsaicin responses in human sensory neurons. Pain 2008, 138, 667-680. [CrossRef] [PubMed]

19. Hermann, H.; de Petrocellis, L.; Bisogno, T.; Schiano Moriello, A.; Lutz, B.; di Marzo, V. Dual effect of cannabinoid CB1 receptor stimulation on a vanilloid VR1 receptor-mediated response. Cell. Mol. Life Sci. 2003, 60, 607-616. [CrossRef] [PubMed]

20. Bhave, G.; Zhu, W.; Wang, H.; Brasier, D.J.; Oxford, G.S.; Gereau, R.W. cAMP-dependent protein kinase regulates desensitization of the capsaicin receptor (VR1) by direct phosphorylation. Neuron 2002, 35, 721-731. [CrossRef]

21. Rathee, P.K.; Distler, C.; Obreja, O.; Neuhuber, W.; Wang, G.K.; Wang, S.-Y.; Nau, C.; Kress, M. PKA/AKAP/VR-1 module: A common link of Gs-mediated signaling to thermal hyperalgesia. J. Neurosci. 2002, 22, 4740-4745.

22. Maione, S.; Bisogno, T.; de Novellis, V.; Palazzo, E.; Cristino, L.; Valenti, M.; Petrosino, S.; Guglielmotti, V.; Rossi, F.; di Marzo, V. Elevation of endocannabinoid levels in the ventrolateral periaqueductal grey through inhibition of fatty acid amide hydrolase affects descending nociceptive pathways via both cannabinoid receptor type 1 and transient receptor potential vanilloid type-1 receptors. J. Pharmacol. Exp. Ther. 2006, 316, 969-982. [CrossRef] [PubMed]

23. Starowicz, K.; Maione, S.; Cristino, L.; Palazzo, E.; Marabese, I.; Rossi, F.; de Novellis, V.; di Marzo, V. Tonic endovanilloid facilitation of glutamate release in brainstem descending antinociceptive pathways. J. Neurosci. 2007, 27, 13739-13749. [CrossRef] [PubMed]

24. Malek, N.; Pajak, A.; Kolosowska, N.; Kucharczyk, M.; Starowicz, K. The importance of TRPV1-sensitisation factors for the development of neuropathic pain. Mol. Cell. Neurosci. 2015, 65, 1-10. [CrossRef] [PubMed]

25. Hwang, S.W.; Cho, H.; Kwak, J.; Lee, S.Y.; Kang, C.J.; Jung, J.; Cho, S.; Min, K.H.; Suh, Y.G.; Kim, D.; et al. Direct activation of capsaicin receptors by products of lipoxygenases: Endogenous capsaicin-like substances. Proc. Natl. Acad. Sci. USA 2000, 97, 6155-6160. [CrossRef] [PubMed]

26. Olah, Z.; Karai, L.; Iadarola, M.J. Anandamide activates vanilloid receptor 1 (VR1) at acidic $\mathrm{pH}$ in dorsal root ganglia neurons and cells ectopically expressing VR1. J. Biol. Chem. 2001, 276, 31163-31170. [CrossRef] [PubMed]

27. Malek, N.; Mrugala, M.; Makuch, W.; Kolosowska, N.; Przewlocka, B.; Binkowski, M.; Czaja, M.; Morera, E.; di Marzo, V.; Starowicz, K. A multi-target approach for pain treatment: Dual inhibition of fatty acid amide hydrolase and TRPV1 in a rat model of osteoarthritis. Pain 2015, 156, 890-903. [CrossRef] [PubMed] 
28. Mifflin, K.A.; Kerr, B.J. The transition from acute to chronic pain: Understanding how different biological systems interact. Can. J. Anesth. 2014, 61, 112-122. [CrossRef] [PubMed]

29. Lim, G.; Sung, B.; Ji, R.-R.; Mao, J. Upregulation of spinal cannabinoid-1-receptors following nerve injury enhances the effects of Win 55,212-2 on neuropathic pain behaviors in rats. Pain 2003, 105, 275-283. [CrossRef]

30. Burston, J.J.; Sagar, D.R.; Shao, P.; Bai, M.; King, E.; Brailsford, L.; Turner, J.M.; Hathway, G.J.; Bennett, A.J.; Walsh, D.A.; et al. Cannabinoid CB2 Receptors Regulate Central Sensitization and Pain Responses Associated with Osteoarthritis of the Knee Joint. PLoS ONE 2013, 8, e80440. [CrossRef] [PubMed]

31. Grim, T.W.; Morales, A.J.; Gonek, M.M.; Wiley, J.L.; Thomas, B.F.; Endres, G.W.; Sim-Selley, L.J.; Selley, D.E.; Negus, S.S.; Lichtman, A.H. Stratification of Cannabinoid 1 Receptor (CB1R) Agonist Efficacy: Manipulation of CB1R Density through Use of Transgenic Mice Reveals Congruence between In Vivo and In Vitro Assays. J. Pharmacol. Exp. Ther. 2016, 359, 329-339. [CrossRef] [PubMed]

32. Kanai, Y.; Nakazato, E.; Fujiuchi, A.; Hara, T.; Imai, A. Involvement of an increased spinal TRPV1 sensitization through its up-regulation in mechanical allodynia of CCI rats. Neuropharmacology 2005, 49, 977-984. [CrossRef] [PubMed]

33. Ji, R.-R.; Samad, T.A.; Jin, S.-X.; Schmoll, R.; Woolf, C.J. p38 MAPK activation by NGF in primary sensory neurons after inflammation increases TRPV1 levels and maintains heat hyperalgesia. Neuron 2002, 36, 57-68. [CrossRef]

34. Obata, K.; Yamanaka, H.; Kobayashi, K.; Dai, Y.; Mizushima, T.; Katsura, H.; Fukuoka, T.; Tokunaga, A.; Noguchi, K. Role of Mitogen-Activated Protein Kinase Activation in Injured and Intact Primary Afferent Neurons for Mechanical and Heat Hypersensitivity after Spinal Nerve Ligation. J. Neurosci. 2004, 24, 10211-10222. [CrossRef] [PubMed]

35. Ma, W.; St-Jacques, B.; Rudakou, U.; Kim, Y.N. Stimulating TRPV1 externalization and synthesis in dorsal root ganglion neurons contributes to PGE2 potentiation of TRPV1 activity and nociceptor sensitization. Eur. J. Pain 2017, 21, 575-593. [CrossRef] [PubMed]

36. Koda, K.; Hyakkoku, K.; Ogawa, K.; Takasu, K.; Imai, S.; Sakurai, Y.; Fujita, M.; Ono, H.; Yamamoto, M.; Fukuda, I.; et al. Sensitization of TRPV1 by protein kinase $\mathrm{C}$ in rats with mono-iodoacetate-induced joint pain. Osteoarthr. Cartil. 2016, 24, 1254-1262. [CrossRef] [PubMed]

37. Luo, X.; Fitzsimmons, B.; Mohan, A.; Zhang, L.; Terrando, N.; Kordasiewicz, H.; Ji, R.-R. Intrathecal administration of antisense oligonucleotide against $\mathrm{p} 38 \alpha$ but not $\mathrm{p} 38 \beta$ MAP kinase isoform reduces neuropathic and postoperative pain and TLR4-induced pain in male mice. Brain. Behav. Immun. 2017. [CrossRef] [PubMed]

38. Miletic, G.; Hermes, J.L.; Bosscher, G.L.; Meier, B.M.; Miletic, V. Protein kinase C $\gamma$-mediated phosphorylation of GluA1 in the postsynaptic density of spinal dorsal horn neurons accompanies neuropathic pain, and dephosphorylation by calcineurin is associated with prolonged analgesia. Pain 2015, 156, 2514-2520. [CrossRef] [PubMed]

39. Kelly, S.; Chapman, R.J.; Woodhams, S.; Sagar, D.R.; Turner, J.; Burston, J.J.; Bullock, C.; Paton, K.; Huang, J.; Wong, A.; et al. Increased function of pronociceptive TRPV1 at the level of the joint in a rat model of osteoarthritis pain. Ann. Rheum. Dis. 2015, 74, 252-259. [CrossRef] [PubMed]

40. Kozak, K.R.; Prusakiewicz, J.J.; Marnett, L.J. Oxidative metabolism of endocannabinoids by COX-2. Curr. Pharm. Des. 2004, 10, 659-667. [CrossRef] [PubMed]

41. Gatta, L.; Piscitelli, F.; Giordano, C.; Boccella, S.; Lichtman, A.; Maione, S.; Di Marzo, V. Discovery of Prostamide F2 $\alpha$ and Its Role in Inflammatory Pain and Dorsal Horn Nociceptive Neuron Hyperexcitability. PLoS ONE 2012, 7, e31111. [CrossRef] [PubMed]

42. Basu, S.; Whiteman, M.; Mattey, D.L.; Halliwell, B. Raised levels of F(2)-isoprostanes and prostaglandin $\mathrm{F}(2 \alpha)$ in different rheumatic diseases. Ann. Rheum. Dis. 2001, 60, 627-631. [CrossRef] [PubMed]

43. Oga, T.; Matsuoka, T.; Yao, C.; Nonomura, K.; Kitaoka, S.; Sakata, D.; Kita, Y.; Tanizawa, K.; Taguchi, Y.; Chin, K.; et al. Prostaglandin F2 $\alpha$ receptor signaling facilitates bleomycin-induced pulmonary fibrosis independently of transforming growth factor- $\beta$. Nat. Med. 2009, 15, 1426-1430. [CrossRef] [PubMed]

44. Telleria-Diaz, A.; Schmidt, M.; Kreusch, S.; Neubert, A.-K.; Schache, F.; Vazquez, E.; Vanegas, H.; Schaible, H.-G.; Ebersberger, A. Spinal antinociceptive effects of cyclooxygenase inhibition during inflammation: Involvement of prostaglandins and endocannabinoids. Pain 2010, 148, 26-35. [CrossRef] [PubMed] 
45. Staniaszek, L.; Norris, L.; Kendall, D.; Barrett, D.; Chapman, V. Effects of COX-2 inhibition on spinal nociception: The role of endocannabinoids. Br. J. Pharmacol. 2010, 160, 669-676. [CrossRef] [PubMed]

46. Palermo, G.; Favia, A.D.; Convertino, M.; de Vivo, M. The Molecular Basis for Dual Fatty Acid Amide Hydrolase (FAAH)/Cyclooxygenase (COX) Inhibition. ChemMedChem 2016, 11, 1252-1258. [CrossRef] [PubMed]

47. De Lange-Brokaar, B.J.E.; Ioan-Facsinay, A.; van Osch, G.J.V.M.; Zuurmond, A.-M.; Schoones, J.; Toes, R.E.M.; Huizinga, T.W.J.; Kloppenburg, M. Synovial inflammation, immune cells and their cytokines in osteoarthritis: A review. Osteoarthr. Cartil. 2012, 20, 1484-1499. [CrossRef] [PubMed]

48. Morera, E.; De Petrocellis, L.; Morera, L.; Moriello, A.S.; Ligresti, A.; Nalli, M.; Woodward, D.F.; Di Marzo, V.; Ortar, G. Synthesis and biological evaluation of piperazinyl carbamates and ureas as fatty acid amide hydrolase (FAAH) and transient receptor potential (TRP) channel dual ligands. Bioorg. Med. Chem. Lett. 2009, 19, 6806-6809. [CrossRef] [PubMed]

49. Guingamp, C.; Gegout-Pottie, P.; Philippe, L.; Terlain, B.; Netter, P.; Gillet, P. Mono-iodoacetate-induced experimental osteoarthritis: A dose-response study of loss of mobility, morphology, and biochemistry. Arthritis Rheum. 1997, 40, 1670-1679. [CrossRef] [PubMed]

50. Chomzynski, P.; Sacchi, N. Single-Step Method of RNA Isolation by Acid Guanidinium ThiocyanatePhenol-Chloroform Extraction. Anal. Biochem. 1987, 162, 156-159. [CrossRef] [PubMed]

(C) 2018 by the authors. Licensee MDPI, Basel, Switzerland. This article is an open access article distributed under the terms and conditions of the Creative Commons Attribution (CC BY) license (http://creativecommons.org/licenses/by/4.0/). 